\title{
A Newborn with Arterial Tortuosity Syndrome: The Importance of Timely Diagnostic Work-Up in Patients Presenting with Cutis Laxa
}

\author{
Karin Pichler ${ }^{1,2, *}$, Elisabeth Ralser ${ }^{3}$, Maria Resch ${ }^{3}$, Elisabeth Steichen-Gersdorf ${ }^{1}$, \\ Kathrin Maurer ${ }^{4}$, Rudolf Trawöger ${ }^{3}$ and Ursula Kiechl-Kohlendorfer ${ }^{3}$ \\ 1 Clinic for Pediatrics I, Inherited Metabolic Disorders, Medical University of Innsbruck, Anichstrasse 35, \\ A-6020 Innsbruck, Austria; elisabeth.steichen@i-med.ac.at \\ 2 Department of Pediatrics, Division of Neonatology, Pediatric Intensive Care and Neuropediatrics, \\ Medical University of Vienna, Waehringer Guertel 18-20, A-1090 Vienna, Austria \\ 3 Department of Pediatrics II, Neonatology, Medical University of Innsbruck, Anichstrasse 35, \\ A-6020 Innsbruck, Austria; elisabeth.ralser@i-med.ac.at (E.R.); maria.resch@tirol-kliniken.at (M.R.); \\ rudolf.trawoeger@i-med.ac.at (R.T.); ursula.kohlendorfer@i-med.ac.at (U.K.-K.) \\ 4 Department of Radiology, Medical University of Innsbruck, Anichstrasse 35, A-6020 Innsbruck, Austria; \\ kathrin.maurer@i-med.ac.at \\ * Correspondence: karin.a.pichler@meduniwien.ac.at; Tel.: +43-1-40400-32320; Fax: +43-1-40400-32380
}

Academic Editor: Giuseppe Musumeci

Received: 6 April 2016; Accepted: 20 May 2016; Published: 1 June 2016

\begin{abstract}
Arterial tortuosity syndrome (ATS) is a rare, autosomal recessively inherited connective tissue disorder characterized by severe and widespread arterial tortuosity of the aorta and of middle-sized arteries with an increased risk of aneurysm, dissection, and stenosis involving either the aorta or the pulmonary arteries or both. In this article, we report the clinical findings and molecular characterization of a newborn with ATS presenting with cutis laxa, respiratory distress, and dislocation of the nasogastric tube due to a gastric volvulus and an open pleuroperitoneal channel. Based on this case report, we emphasize early diagnostic work-up in all patients presenting with cutis laxa in order to prevent adverse cardiovascular events. Data suggests that early diagnosis is life-saving in these patients.
\end{abstract}

Keywords: arterial tortuosity syndrome; cutis laxa; SLC2A10/GLUT10

\section{Introduction}

Arterial tortuosity syndrome (ATS) is a rare, autosomal recessively inherited connective tissue disorder characterized by severe and widespread arterial tortuosity of the aorta and of middle-sized arteries with an increased risk of aneurysm, dissection, and stenosis involving either the aorta, the pulmonary arteries, or both. Additional characteristics include dysmorphic facial features (high palate and dental crowding, micrognathia, large ears, long face, convex nasal ridge), soft/doughy skin, cutis laxa, and signs of a generalized connective tissue disorder such as skeletal manifestations (scoliosis, pectus excavatum/carinatum, joint laxity, congenital contractures, arachnodactyly), hernias (inguinal, diaphragmatic, hiatal), muscular hypotonia, or ocular involvement (myopia, keratokonus) [1]. Prognosis varies from early mortality due to cerebral infarctions and respiratory failure following pulmonary hypertension due to pulmonary stenosis and aneurysms to minor manifestations in adulthood [2]. ATS is caused by mutations in the SLC2A10 gene-encoding glucose transporter 10 (GLUT10). An in vitro study showed that GLUT10 is predominately expressed in smooth muscle cells and insulin-stimulated adipocytes. It facilitates transport of the oxidative stress-protecting agent L-dehydroascorbic acid (DHA), the oxidized form of vitamin C, into mitochondria [3]. However, 
its specific role in the pathogenesis of ATS is still unclear, just as its exact localization within the endoplasmic reticulum and all the transported substances (including D-glucose, D-galactose, 2-deoxy-D-glucose). ATS is a rare genetic disorder that occurs in all populations, but most reviews have been from Europe and the Middle East [1,2].

In this article, we report the clinical findings and molecular characterization of a newborn with ATS presenting with cutis laxa, respiratory distress, and dislocation of the nasogastric tube due to a hiatal hernia after birth.

\section{Case Report}

A female neonate was born from Albanian immigrants via cesarean section, because of oligohydramnios and a suspicion the baby would be post-term. There was no prenatal care during pregnancy until approximately 32 weeks gestational age. It was the second child of consanguineous (second-degree cousins), unaffected parents. The infant was transferred from a rural hospital to a tertiary referral hospital immediately after birth due to respiratory distress and a choanal stenosis, as well as the inability to orally insert a nasogastric tube. Further investigations exhibited dysmorphic features like high palate, micrognathia, large ears, elongated face, and cutis laxa, but normal biometric data (Figure 1). Chest radiography showed prominent skin wrinkles and was also suggestive of an open pleuroperitoneal channel. The nasogastric tube was positioned in the mid-third of the oesophagus; the stomach bubble was not visible, but bright vesicles were detected in the basal part of the thorax so that an esophagial atresia was likely. However, this could be excluded by a chest X-ray with a water-soluble contrast agent, demonstrating passage of the contrast agent through a kinked esophagus into the stomach, which was shifted into the thorax through a hiatal hernia (Figure 2b,c). Subsequent hiatal hernia repair surgery revealed organoaxial volvulus of the stomach, which explained why the nasogastric tube was not able to pass the cardia and remained in the esophagus. Echocardiography was highly suggestive of a stenosis of the pulmonary arteries (PAS) following a dilated truncus pulmonalis, which could be confirmed by a CT-angiography. The latter further illustrated an elongated aorta with kinking at the level of the aortic arch (thoracic vertebrae 2/3) as well as multiple elongated and tortuous mid-sized arteries. None of them showed aneurysmatic alterations (Figure 2a). No abnormalities were found in an EEG, a head ultrasound, an ophthalmologic evaluation, or the skeletal system.

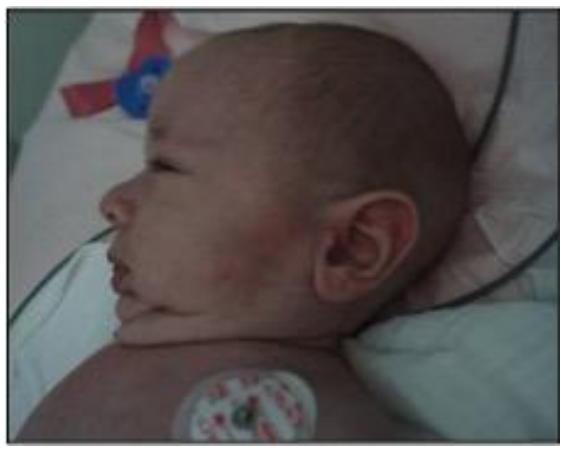

(a)

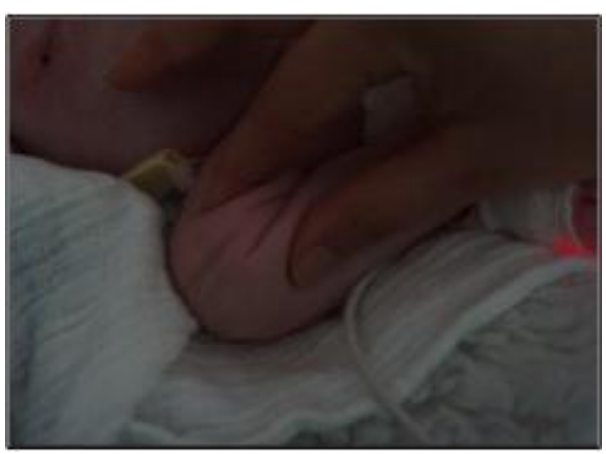

(b)

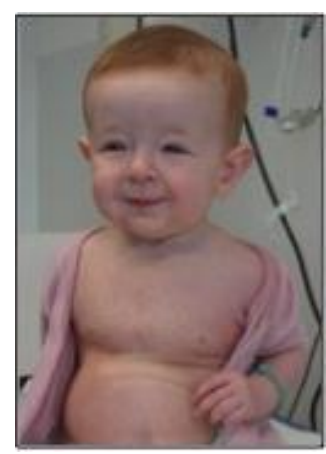

(c)

Figure 1. The herein reported patient at the age of 3 days $(\mathbf{a}, \mathbf{b})$ and 8 months (c) presenting with dysmorphic features tipical for arterial tortuosity syndrome (ATS), i.e., high palate, micrognathia, large ears, elongated face, and cutis laxa.

Based on these clinical findings suggestive of ATS, the SLC2A10 gene was sequenced reporting a homozygous mutation of the c.685C $>\mathrm{T}\left(\mathrm{p} . \mathrm{Arg} 229^{*}\right)$ in exon 2 , which has already been reported in infants affected from ATS [2]. 


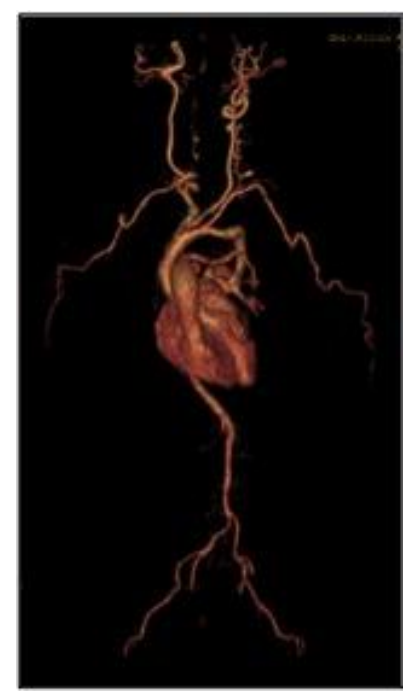

(a)

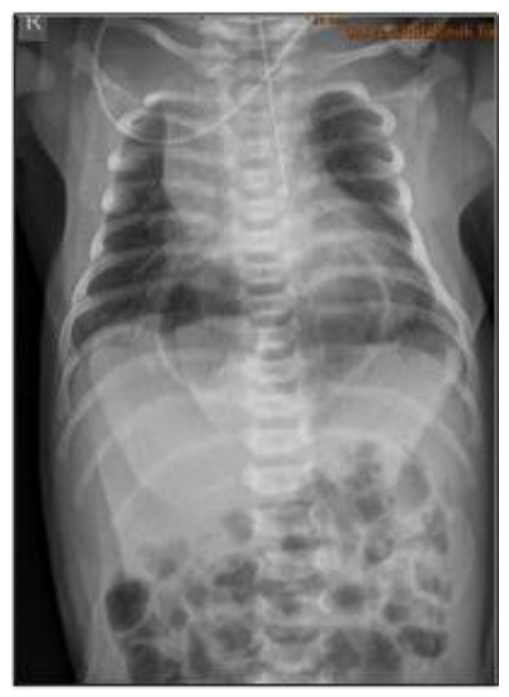

(b)

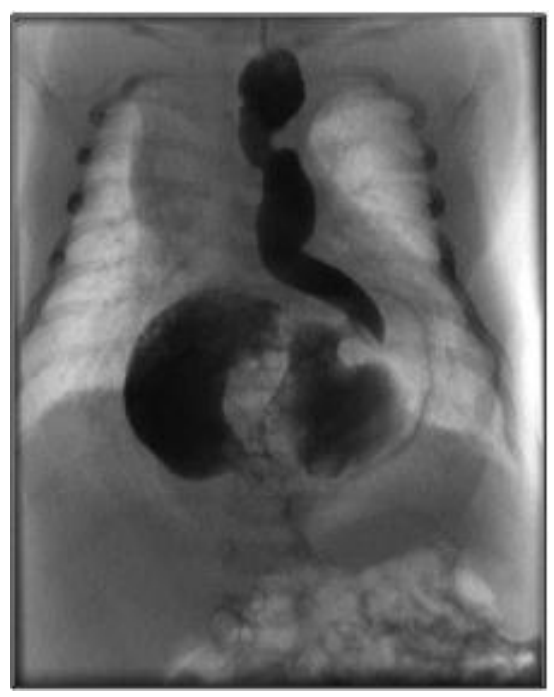

(c)

Figure 2. (a) CT-angiography revealed stenosis of the pulmonary arteries (PAS) following a dilated truncus pulmonalis as well as an elongated aorta with kinking at the level of the aortic arch and multiple elongated and tortuous mid-sized arteries. None of them showed aneurysmatic alterations; (b) Chest radiography showed prominent skin wrinkles and was also suspicious of an open pleuroperitoneal channel. The nasogastric tube was positioned in the mid-third of the oesophagus; the stomach bubble was not visible, but bright vesicles were detected in the basal part of the thorax so that an esophagial atresia was likely; (c) However, this could be excluded by a chest X-ray with a water-soluble contrast agent demonstrating passage of the contrast agent through a kinked esophagus into the stomach, which was shifted into the thorax through a hiatal hernia.

The axial hiatal hernia was surgically repaired without any complications, particularly without any signs of wound healing disturbance, which has been reported in these patients [4]. Our patient continued having slight, spontaneously resolving desaturations, most likely due to the PAS. She was discharged at the age of 14 days without any medical therapy. Cardiological follow-up including echocardiography was scheduled in six-week intervals to monitor PAS. So far, PAS in our patient has not deteriorated, and no intervention has therefore been necessary. Because of the benign clinical course, follow-ups have now been extended to three-month intervals. Written informed consent was obtained from the patient's parents for publications of this case report and accompanying images.

\section{Discussion}

The leading clinical symptoms of the herein reported patient were cutis laxa, malposition of the nasogastric tube, and respiratory distress. Cutis laxa is suggestive of a generalized connective tissue disorder. Differential diagnosis include occipital horn syndrome, autosomal recessive cutis laxa type IA, IB, and IC, Loeys-Dietz syndrome, and ATS. All of these syndromes are associated with cardiovascular complications of varying, but mostly severe, degrees and absolutely warrant extensive cardiovascular imaging and genetic work-up. The second symptom, i.e., the inability to properly insert a nasogastric tube initially was highly suspicious for oesophagus atresia but could be ruled out by a chest X-ray with a water-soluble contrast agent demonstrating passage of the contrast agent through a kinked esophagus into the stomach, which was shifted into the thorax through a hiatal hernia. Subsequent hiatal hernia repair surgery revealed organoaxial volvulus of the stomach, which explained why the nasogastric tube was not able to pass the cardia and remained in the esophagus. The last clinical symptom, i.e. respiratory distress and subsequent self-limiting desaturatins, from our patient was caused by the PAS. As previously described, patients suffering from ATS are especially at risk for aneurysms and dissections as well as ischemic vascular events involving cerebral and abdominal 
arteries [1]. However, the most critical cardiovascular feature in ATS is the PAS. The degree of the PAS is directly related to clinical outcome [5]. Especially the first years of life have been reported to be critical and may go along with potentially life-threatening events [6,7]. Therefore, early diagnosis along with consistent follow-ups and timely cardiovascular surgery, if needed, is mandatory. The risks of lethal events during cardiovascular surgery did not seem to be higher patients with ATS [5,8,9]. In 2004, Wessels et al. observed that ATS is fatal before the age of 5 years in $40 \%$ of the patients [10]. Today, we are aware that early diagnosis is life-saving, and most patients survive into adulthood. Better knowledge of this disease as well as adequate monitoring and close follow-up increased life expectancy of patients with ATS. Even four successful pregnancies in patients with ATS after multidisciplinary management have been reported $[8,11]$. Complications that may occur in adulthood include chronic systemic pulmonary hypertension, heart conduction defects, aortic root dilatation, stroke, and intracranial aneurysms [8]. Therefore, patients with ATS necessitate life-long specific attention and management. We are the first to report choanal stenosis in a patient with ATS. However, this might be fortuitous.

\section{Conclusions}

Based on this case report, we emphasize early diagnostic work-up in all patients presenting with cutis laxa in order to prevent adverse cardiovascular events if the clinical course is severe. Data suggest that early diagnosis is life-saving in these patients.

Author Contributions: Karin Pichler, Elisabeth Ralser, Elisabeth Steichen-Gersdorf and Rudolf Trawöger were involved in diagnosis and treatment of the reported patients as well as in data collection. Kathrin Maurer was the main responsible for the interpretation of the radiological findings of the patient. Karin Pichler and Maria Resch drafted the manuscript, helped by Ursula Kiechl-Kohlendorfer, which also supervised the study.

Conflicts of Interest: The authors declare no conflict of interest.

\section{Abbreviations}

The following abbreviations are used in this manuscript:

$\begin{array}{ll}\text { ATS } & \text { arterial tortuosity syndrome } \\ \text { GLUT10 } & \text { glucose transporter } 10 \\ \text { DHA } & \text { L-dehydroascorbic acid } \\ \text { PAS } & \text { pulmonary artery stenosis } \\ \text { CT } & \text { computer tomography } \\ \text { EEG } & \text { electroencephalography }\end{array}$

\section{References}

1. Callewaert, B.; de Paepe, A.; Coucke, P. Arterial tortuosity syndrome. In GeneReviews ${ }^{\circledR}$; Pagon, R.A., Adam, M.P., Ardinger, H.H., Wallace, S.E., Amemiya, A., Bean, L.J.H., Bird, T.D., Fong, C.T., Mefford, H.C., Smith, R.J.H., et al., Eds.; University of Washington: Seattle, WA, USA, 2014.

2. Callewaert, B.L.; Willaert, A.; Kerstjens-Frederikse, W.S.; de Backer, J.; Devriendt, K.; Albrecht, B.; Ramos-Arroyo, M.A.; Doco-Fenzy, M.; Hennekam, R.C.; Pyeritz, R.E.; et al. Arterial tortuosity syndrome: Clinical and molecular findings in 12 newly identified families. Hum. Mutat. 2008, 29, 150-158. [CrossRef] [PubMed]

3. Lee, Y.C.; Huang, H.Y.; Chang, C.J.; Cheng, C.H.; Chen, Y.T. Mitochondrial GLUT10 facilitates dehydroascorbic acid import and protects cells against oxidative stress: Mechanistic insight into arterial tortuosity syndrome. Hum. Mol. Genet. 2010, 19, 3721-3733. [CrossRef] [PubMed]

4. Castori, M.; Ritelli, M.; Zoppi, N.; Molisso, L.; Chiarelli, N.; Zaccagna, F.; Grammatico, P.; Colombi, M. Adult presentation of arterial tortuosity syndrome in a 51-year-old woman with a novel homozygous c.1411+1G $>\mathrm{A}$ mutation in the SLC2A10 gene. Am. J. Med. Genet. A 2012, 158A, 1164-1169. [CrossRef] [PubMed]

5. Al-Khaldi, A.; Mohammed, Y.; Tamimi, O.; Alharbi, A. Early outcomes of total pulmonary arterial reconstruction in patients with arterial tortuosity syndrome. Ann. Thorac. Surg. 2011, 92, 698-704. [CrossRef] [PubMed] 
6. Takahashi, Y.; Fujii, K.; Yoshida, A.; Morisaki, H.; Kohno, Y.; Morisaki, T. Artery tortuosity syndrome exhibiting early-onset emphysema with novel compound heterozygous SLC2A10 mutations. Am. J. Med. Genet. A 2013, 161A, 856-859. [CrossRef] [PubMed]

7. Moceri, P.; Albuisson, J.; Saint-Faust, M.; Casagrande, F.; Giuliano, F.; Devos, C.; Benoit, P.; Hugues, N.; Ducreux, D.; Cerboni, P.; et al. Arterial tortuosity syndrome: Early diagnosis and association with venous tortuosity. J. Am. Coll. Cardiol. 2013, 61. [CrossRef] [PubMed]

8. Ritelli, M.; Chiarelli, N.; Dordoni, C.; Reffo, E.; Venturini, M.; Quinzani, S.; Monica, M.D.; Scarano, G.; Santoro, G.; Russo, M.G.; et al. Arterial tortuosity syndrome: Homozygosity for two novel and one recurrent SLC2A10 missense mutations in three families with severe cardiopulmonary complications in infancy and a literature review. BMC Med. Genet. 2014, 15. [CrossRef] [PubMed]

9. Ekici, F.; Uçar, T.; Fitöz, S.; Atalay, S.; Tutar, E. Cardiovascular findings in a boy with arterial tortuosity syndrome: Case report and review of the literature. Turk. J. Pediatr. 2011, 53, 104-107. [PubMed]

10. Wessels, M.W.; Catsman-Berrevoets, C.E.; Mancini, G.M.; Breuning, M.H.; Hoogeboom, J.J.; Stroink, H.; Frohn-Mulder, I.; Coucke, P.J.; Paepe, A.D.; Niermeijer, M.F.; et al. Three new families with arterial tortuosity syndrome. Am. J. Med. Genet. A 2004, 131, 134-143. [CrossRef] [PubMed]

11. Allen, V.M.; Horne, S.G.; Penney, L.S.; Rapchuk, I.L.; Brock, J.A.; Thompson, D.L.; Stinson, D.A. Successful outcome in pregnancy with arterial tortuosity syndrome. Obstet. Gynecol. 2009, 114, 494-498. [CrossRef] [PubMed]

(C) 2016 by the authors; licensee MDPI, Basel, Switzerland. This article is an open access article distributed under the terms and conditions of the Creative Commons Attribution (CC-BY) license (http://creativecommons.org/licenses/by/4.0/). 